\title{
Fight against Childhood Malnutrition - A Must Win Battle
}

\section{Shakeel Ahmed}

Child growth is internationally recognized as an important indicator of nutritional status and health of the nation by which the nutritional status of the population can be assessed. Nutritional imbalance results in under nutrition (underweight, wasting and stunting) and over nutrition (overweight \& obesity).

Malnutrition is defined as not having enough energy or nutrients to live a physically active life that allows for optimal health. Malnutrition is one of the most amendable threats to global health and child survival especially in poor and under developed settings. Pakistan positions highest in the world in childhood malnutrition and plays a substantial role in the country's elevated child morbidity and mortality. Is still the leading contributing cause of deaths in less than five years of age that directly or indirectly contributes to almost $55 \%$ of all under- 5 deaths in the country consequently affecting the future health and socioeconomic progress and creative potential of the community.

For last many decades we have been fighting a battle against the threat of malnutrition but there has been little change in the prevalence of malnutrition in the country over the last two decades, despite adequate food availability and an improvement in the overall socioeconomic status. According to a recent report issued by UNICEF, Pakistan ranks $22^{\text {nd }}$ in under five mortality with the rate of 81 per 1000 live births and the infant mortality rate is 66 per 1000 live births with minimal improvement in last twenty years. In most of these deaths besides the primary illness, malnutrition is an additional contributing factor. Despite a multitude of programs in place, the country's nutrition gauges seem to be at a standstill. If it still the same for next few years then there are high probability that we reach to the point where national nutrition emergency will be declared.

The last National Nutrition Survey (NNS), which was conducted in 2011, revealed the alarming burden of malnutrition in children, with high prevalence in children under five years of age. About 44 per cent of Pakistani children suffer from stunting (very low height for age), indicating chronic malnutrition. 15 percent suffer from wasting, indicating acute malnutrition, while: 31.5 percent are underweight which exceeds the international emergency threshold. 63 percent of children are anemic. Only 38 percent of children are exclusively breast fed for first 6 months.

The Community-based Management of Acute Malnutrition (CMAM) programme assesses and provides malnourished

Shakeel Ahmed
Professor, Department of Paediatrics
Bahria University Medical and Dental College
Received: 12-06-18
Accepted: 12-07-18

children and mothers with supplementary foods for homebased care. UNICEF supported the dissemination of new CMAM guidelines in 2015 and trained over 12,000 health care providers. UNICEF initiated a stunting reduction program in Sindh targeting 800,000 children and women. In 2015, a national Infant and Young Child Feeding (IYCF) strategy was developed and endorsed with UNICEF support, with guidelines and a communication strategy in development. This will help ensure that mothers and caregivers are aware of, and follow, good feeding practices, and thus reduce malnutrition in Pakistan.

Moreover, a main reason of malnutrition in our children is generally the poor state of feeding practices. Pakistan is evident for being the lowest rates for the exclusive breastfeeding and timely commencement of initiation of soft diet to young infants. Data from the Pakistan Demographic and Health Survey (2012-2013) suggests that early initiation of breastfeeding is observed only in 18 percent of all births, whereas exclusive breastfeeding is carried out for only 38 percent of infants younger than six months. The free marketing and promotion of infant formulas is a recognized obstacle for exclusive breastfeeding. Despite the existence of legislation to discourage such practices in the country; many health providers still breach the code for exclusive breastfeeding. Moreover, low literacy rates among women, lack of their empowerment, early marriages, large family size, and poor access to healthcare facilities are other contributing factors of malnutrition among our children.

We strongly feel that investment in health and nutrition is considered to be a moral responsibility of the policy makers. More often than in every field of life everyone has to play their role in this battle. Government and policy makers have a pivotal role in this battle. As Pakistan is on a dangerous downward route; we need to look outside the traditional models and to leverage new and innovative projects already in place for greater impact. This is a high time to adopt both short and long terms strategies through public/private partnership so that we as a nation can get rid of this hazard.

\section{REFERENCES:}

1. Blossner M, de Onis M. Malnutrition: quantifying the health impactat national and local levels. Geneva, Switzerland: World Health Organization; 2005.

2. Environmental Burden of Disease Series. (Online) 2011. Available from URL: http://whqlibdoc.who. int/ publications/ 2005/9241591870. pdf.

3. United Nations. We Can End Poverty 2015: Millennium Development Goals, United Nations, 2011. URL: http:// www.un.org/en/mdg/summit2010/.

4. Finlay JE, Ozaltin E, Canning D. The association of maternal age with infant mortality, child anthropometric failure, diarrhoea and anemia for first births: evidence from 55 lowand middle-income countries. BMJ Open 2011; 1: e000226. 
5. Government of Pakistan, National Nutritional Survey of Pakistan, 2001-2, Islamabad.

6. WHO, "UN Inter-agency assessment mission on impact of food crisis in Pakistan, Impact of food crisis on health" 2008.

7. Bhutta ZA. The enigma of maternal and childhood malnutrition in Pakistan: can we break the vicious cycle? Journal of College of Physicians \& Surgeons, Pakistan. 2002.

8. Government of Pakistan. Pakistan economic survey 2001-2, economic advisors wing, finance division, Islamabad.
9. Bhutta ZA, Soofi SB, Atif H. Pakistan National Nutrition Survey, 2011 Aga Khan University.

10. Pakistan demographic and health survey 2012-13 National Institute of Population Studies Islamabad, Pakistan December 2013.

11. Finlay, J E., Ozaltin E., Canning D. The association of maternal age with infant mortality, child anthropometric failure, diarrhea and anemia for first births. BMJ Open 2011 (1), no. 2: e000226. 